\title{
Morphological Characteristics of Lungs with Experimental Peritonitis on the Background of Diabetes Mellitus
}

\author{
Ihor Ya. Dziubanovskyi ${ }^{1}{ }^{\mathbb{D}}$, Svitlana R. Pidruchna ${ }^{2, *}{ }^{\mathbb{D}}$, Bohdana M. Verveha ${ }^{3}$, \\ Igor V. Zhulkevych ${ }^{4}$ id , Nataliia A. Melnyk ${ }^{5}$, Olga B. Svan ${ }^{6}$ iD \\ 1 Department of Surgery of Postgraduate Faculty, Horbachevsky Ternopil National Medical University - Ternopil, \\ Ukraine \\ 2 Department of Medical Biochemistry, I. Horbachevsky Ternopil National Medical University - Ternopil, Ukraine \\ 3 Department of pathological physiology, Danylo Halytsky Lviv National Medical University - Lviv, Ukraine \\ 4 Department of Oncology, Radiology, and Therapy and Radiation Medicine, I. Horbachevsky Ternopil National Medical \\ University, Ternopil, Ukraine ${ }^{5}$ Department of ${ }^{5}$ Department of General Hygiene and Ecology, I. Horbachevsky Ternopil \\ National Medical University - Ternopil, Ukraine \\ 6 Department of Disaster and Military Medicine, I. Horbachevsky Ternopil National Medical University - Ternopil, Ukraine \\ * corresponding author e-mail address: pidruchna@tdmu.edu.ua;
}

Scopus Author ID 55203650400

Received: 10.04.2020; Revised: 8.06.2020; Accepted: 10.06.2020; Published: 17.06.2020

\begin{abstract}
Acute generalized peritonitis (AGP) and diabetes mellitus (DB) remains an urgent problem in modern medicine, as rapid disability and high mortality have been leading to cardiovascular disease and oncology pathology in recent years. The purpose is to study and evaluate the morphological changes in the lungs in animals with experimental AGP against the background of DM. In the experiment, 32 white rats were used. The main group consisted of 24 animals with simulated AGP against the background of CD; control group - 8 intact animals. The experimental CD was reproduced by intraperitoneal administration of streptozotocin at a dose of $60 \mathrm{mg} / \mathrm{kg}$. On the 14th day after administration of streptozotocin, animals of the main group were injected with $10 \%$ filtered stool suspension into the abdominal cavity of the study rats at a dose of $0.5 \mathrm{ml}$ per $100 \mathrm{~g}$ of body weight. Removal of material for histological examination was carried out on days 1, 3, and 7. For the morphological study of the lungs of rats under experimental peritonitis, the method of light microscopy was used. Micropreparations were stained with hematoxylin and eosin, according to Hart, by the Van Gizon method. Histological examination of the lung tissue of animals with simulated AGP against the background of CD compared with intact rats on day 1 of the experiment showed a tendency for vasodilation. For 3 days, the lungs of the organs were observed in the lungs of animals; the wall was thickened in the vessels of large and medium caliber, the phenomena of mucoid edema and perivascular edema with small cell infiltration were noted. At day 7, significant changes in blood vessels and bronchi in all components were detected in the lungs of animals; Perivascular edema and inflammatory infiltration along the interval septa were observed in animals with simulated AGP against the background of CD in comparison with intact rats for 1 day of the experiment in lung tissue. The wall of small bronchi was thickened by leukocyte infiltration. For 3 days, the lungs of the animals were observed full blood vessels of the pulmonary components, the phenomena of mucoid edema were noted. For 7 days in the lungs of animals found the expansion of the lumen of the arteries and veins from their full blood, thickening of the outer shell of the vessel wall.
\end{abstract}

Keywords: morphological changes of the lungs; acute generalized peritonitis; diabetes mellitus.

(C) 2020 by the authors. This article is an open-access article distributed under the terms and conditions of the Creative Commons Attribution (CC BY) license (https://creativecommons.org/licenses/by/4.0/).

\section{Introduction}

Acute generalized peritonitis (AGP) and diabetes mellitus (DM) remains an urgent problem in modern medicine, as rapid disability and high mortality have been leading to cardiovascular disease and oncology pathology in recent years.

In AGP, acute respiratory distress syndrome develops in $25-42 \%$ of cases. Pulmonary complications and the development of respiratory failure in peritonitis significantly impair the prognosis of the disease, which ultimately leads to high mortality. The leading factors in the 
pathogenesis of the aerohematic barrier disturbance are the increase in blood levels of toxic compounds, including endotoxin, disorders of intra-organ hemodynamics, tissue hypoxia; acidosis; damage to the lung surfactant system $[1,2]$. Pulmonary hemocapillaries become the first link for mediators and endotoxins, and the lungs are the first organ in the path of their detoxification. As a consequence, there is a development of the surfactant system dysfunction associated with phospholipid metabolism as well as damage to the aerohematic barrier [3]. This is explained by the structural and functional features of the respiratory system and the direct action of biological components of the mediator cascade on its metabolic functions, contributing to disorders of microcirculation. In this case, the activation of immunocompetent cells, accompanied by a "respiratory burst" and the release of a large number of inflammatory mediators. As a consequence, the endothelial permeability of the hemocapillaries of the lungs increases, their respiratory and non-respiratory functions are impaired, and irreversible changes in hemodynamics develop with the progression of acute respiratory distress syndrome.

The late vascular complications of diabetes - micro- and macroangiopathy [4-15] have been not sufficiently studied to date, but they are the cause of the premature death of nondisabled people. In current clinical guidelines, diabetes is considered as a risk factor for nonspecific lung disease, which is explained by impaired immune status in these patients [1620].

Some foreign pathomorphologists show that diabetic microangiopathy develops in the capillaries of the alveolar septum, arterioles of the lungs and pleura. However, these data are disparate and contradictory [8].

Despite the relevance of a large number of studies on vascular system involvement in AGP and DM, a lot of clinical and morphological aspects of this problem remain debatable. The issue of the interdependence of diabetic angiopathies and acute peritonitis is not fully addressed. Solitary works devoted to pathomorphological studies of the vessels of the lung indicate a violation of the structure of arterioles and capillaries, which are characteristic of diabetic micro- and macroangiopathy $[9,10]$. Our study is dedicated to solving this problem.

The purpose is to study and evaluate the morphological changes in the lungs in animals with experimental AGP against the background of DM.

\section{Materials and Methods}

The experiment used 32 white rats, which were divided into three groups: the main group - 24 animals with simulated AGP against the background of CD; the control group consisted of 8 intact animals kept in standard vivarium conditions. All groups of animals compared were representative by weight, sex, and age. This experimental study was conducted in compliance with the general rules and regulations of the European Convention for the Protection of Vertebrate Animals, which are used for research and other scientific purposes (Strasbourg, 1986), the General Ethical Principles of Experiments on Animals (Kyiv, 2001) and the Law of Ukraine «On the Protection of Animals from Animals Abuse» (2006).

The experimental $\mathrm{CD}$ was reproduced by intraperitoneal administration of streptozotocin at a dose of $60 \mathrm{mg} / \mathrm{kg}$ ("Sigmal", which was dissolved in a sodium citrate buffer pH 4.5). Glucose studies were performed at 9:00 am with experimental animals free access to food and water during the night period. Insulin (0-2 units subcutaneously two to five times a week) was administered to rats throughout the observation period.

After 2 weeks from the use of streptozotocin in rats from venous blood, which was obtained from the tail vein, glucose content was determined, but in subsequent studies, only 
those rats in which glucose content was greater than $300 \mathrm{mg} / \mathrm{L}$ were observed. Animals of the control group were administered subcutaneously sterile $0.9 \%$ sodium chloride solution instead of streptozotocin [11].

The influence of CD on the course of AGP was studied on the model proposed by V.A. Lazarenko et al. [12]. This model is close to a similar process in humans in terms of etiological factors, clinical manifestations, and phase of the course. On the 14th day after administration of streptozotocin, animals of the main group were injected with $10 \%$ filtered stool suspension into the abdominal cavity of the study rats at a dose of $0.5 \mathrm{ml}$ per $100 \mathrm{~g}$ of body weight. Rats of the comparison group received only a subcutaneous injection of fecal suspension. The stool suspension was obtained by mixing isotonic saline and fecal matter with 2-3 intact animals, then filtered twice through a double layer of gauze. This suspension was injected into the intact rats in a puncture manner no later than 20 min after preparation. In order to avoid damage to the internal organs when the stool suspension was introduced into the abdominal cavity, the animals were kept upright, with a caudal end up. By the method of puncture of the ventral wall in the center of the midline of the abdomen, directing the end of the needle alternately into the right and left hypochondrium, right and left iliac areas, the same amount of stool suspension was administered.

The control group consisted of intact animals kept in standard vivarium conditions. The removal of material for histological examination was carried out on days 1, 3, and 7 after the animals were removed from the experiment by their decapitation under thiopental anesthesia. For the morphological study of the lungs of rats under experimental peritonitis, the method of light microscopy was used. Pieces of lung tissue, no more than $0.5 \mathrm{~cm}$ thick, were taken in $10 \%$ neutral formalin solution. After fixation, the material was washed, dewatered by appropriate conduction through solutions of increasing concentration of alcohol, passed through chloroform and chloroform-paraffin mixture, and poured into paraffin blocks [13]. Sections 7$8 \mu \mathrm{m}$ thick were prepared on a dome microtome. Micropreparations were stained with hematoxylin and eosin, according to Hart, by the Van Gizon method. The study of micro preparations was carried out using a light microscope company "Olympus". Photomicrographs were taken using a digital camera coupled with a C 3040-A DUP.

\section{Results and Discussion}

Microscopic changes in the structural components of the lungs of intact animals (Fig. 1). In these animals, the interalveolar septa (alveolar wall, which is typical for two adjacent alveoli) were slightly thickened by the expansion and fullness of the capillaries and the formation of small-cell infiltrates. The lumps of the alveoli were free of exudate and cellular elements. Large and medium-sized vessels expanded, contained erythrocyte clusters, but their walls varied little, perivascular edema was insignificant.

The luminal bronchial tubes and bronchioles did not expand, the ciliated epithelium was not damaged, and the lymphoid tissue of the peribronchial sites was similar to that in intact animals.

After 1 day of the experiment in the lungs of animals with AGP on the background of CD observed a tendency to vasodilation, which led to the development of perivascular edema (Fig. 2).

The structural components of acini varied little compared to the previous group, emphysematous manifestations continued to grow, along with the spread of inflammatory infiltration along the interval septa. The wall of the small bronchi was moderately thickened, 
mainly due to leukocyte infiltration. The bronchioles were free from the exudate and cellular elements.

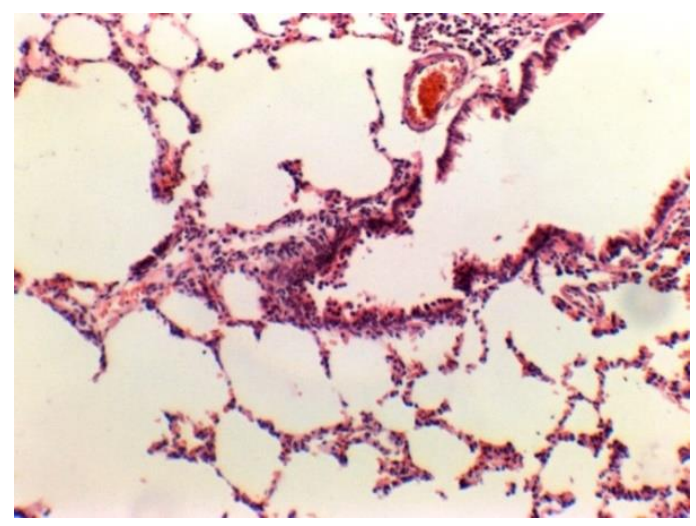

Figure 1. Microscopic organization of lungs of intact animals. Structural state of acini, mild peribronchial leukocyte infiltration. Staining with hematoxylin and eosin. $\times 100$.

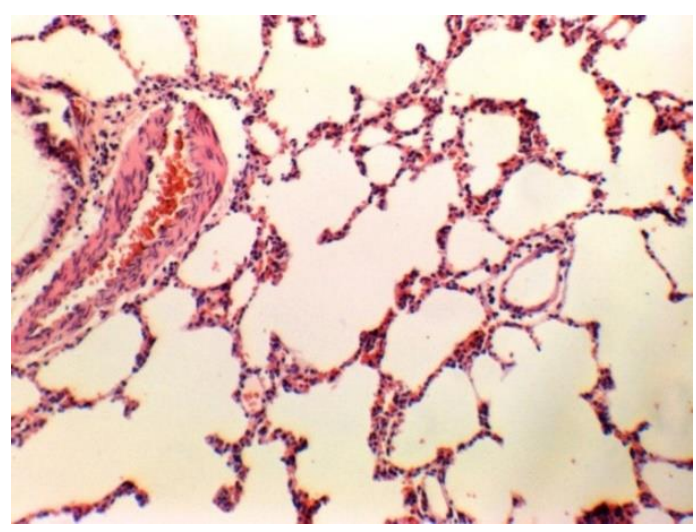

Figure 2. Microscopic changes in the lungs of animals 1 day after the simulated AGP against the background of CD. Edema of the artery wall, emphysematous expansion of the alveoli. Staining with hematoxylin and eosin.

$$
\times 100
$$

After 3 days of experiment in animals with AGP against the background of DM in the lungs of the animals observed, the anemia of vascular components of the organ, in the vessels of large and medium caliber thickened wall, noted the phenomena of mucoid edema and perivascular edema with small cell infiltration. The bronchial wall was also thickened by swelling and lymphohistiocytic infiltration of the adventitia; in some areas, the permeability of the vascular wall was increased, which was manifested by small diapedesis hemorrhages. Single erythrocytes were also found in the lumen of the alveoli, most of which contained serious or serous leukocyte exudates (Fig. 3).

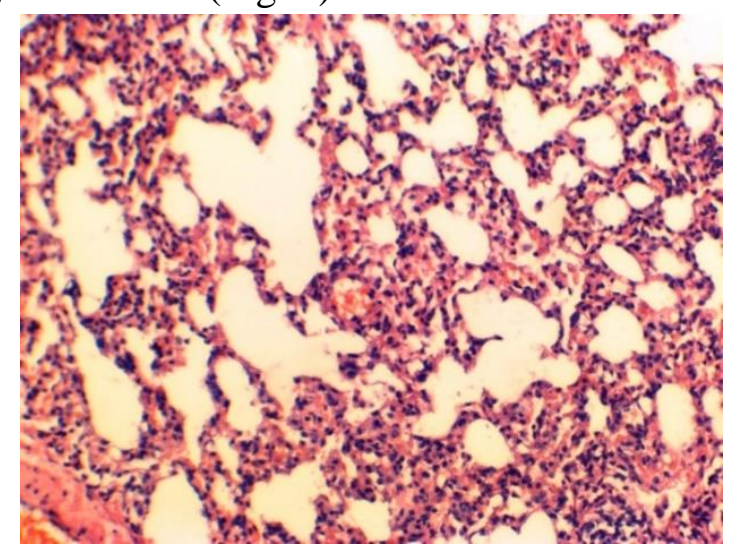

Figure 3. Microscopic changes in the lungs of animals 3 days after the simulated AGP against the background of CD. Edema of the artery wall, emphysematous expansion of the alveoli. Staining with hematoxylin and eosin. $\times 100$ 
On day 7, after modeling of AGP against the background of CD in the lungs of animals, revealed significant changes in blood vessels and bronchi.

Vascular disorders of the organ were observed in all components. The enlargement of the lumen of the arteries and veins was accompanied by their full blood. The walls of many vessels were thickened by the swelling of the outer shell. Perivascular edema increased.

The structural organization of the bronchial wall has changed significantly. The ciliated epithelium of the mucous membrane was damaged, its partial desquamation was noted. Adventurous sheath edema was accompanied by leukocyte infiltration — detected spasm of the small bronchial lumen, thickening of their muscular plate.

In respiratory departments of lungs revealed alveoli of different areas. Part of the structures was significantly enlarged (the phenomenon of emphysema), part was narrowed due to the thickened interval sections (Fig. 4).

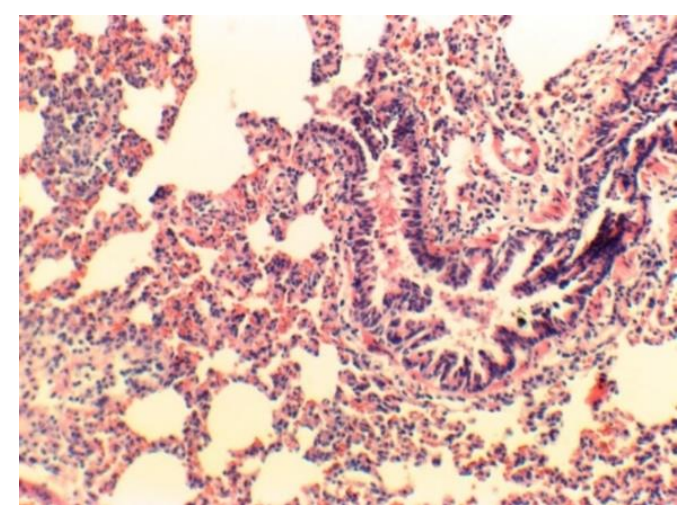

Figure 4. Histological changes in the lungs of the animal 7 days after the simulated AGP against the background of the CD. Disorders of the structure of the bronchus and alveoli. Staining with hematoxylin and eosin. $\times 100$.

In the study of histological sections of the lungs in all groups of animals studied showed signs of acute lung injury in response to the effect of the damaging factor. Damage to the endothelium of the capillaries, their basal membranes leads to increased vascular permeability and the appearance of interstitial, and subsequently alveolar pulmonary edema, disorders of microcirculation, erythrocyte aggregation, stasis and blood clots [20-26]. The increase in the content of segmental neutrophils, macrophages, lymphocytes in the interval septa reflects the reaction of adaptation and the immune system in the conditions of action of the damaging factor, namely. Emerging atelectasis and diselectasis are a consequence of an obstruction of the bronchial secretion, which leads to obstruction of the bronchial secretion, which leads to increased dead space, damage to the alveoli endothelium, progression of hypoxia. Reception into the interstitium of water, electrolytes, albumin enhances connective tissue edema. With further progression, the interstitial fluid enters the alveoli [27-34].

Morphological signs of acute lung injury are nonspecific and do not depend on the etiological factor. In acute lung injury, aggression factors lead to damage to the endothelium of the pulmonary capillaries, their basement membrane, increase in capillary permeability, accumulation of extracellular fluid and exudate of proteins with the formation of pulmonary edema.

\section{Conclusions}

Histological examination of the lung tissue of animals with modeled AGP against the background of CD compared with intact rats on day 1 of the experiment showed a tendency for 
vasodilation, which led to the development of perivascular edema, the spread of inflammatory infiltration along the interval septa. The wall of the small bronchi was moderately thickened, mainly due to leukocyte infiltration. For 3 days in animals with AGP against the background of $\mathrm{CD}$ in the lungs of the animals observed, the anemia of vascular components of the organ, in the vessels of large and medium caliber thickened the wall, noted the phenomena of mucoid edema and perivascular edema with small cell infiltration. At day 7, modeling of AGP against the background of CD in the lungs of animals revealed significant changes in blood vessels and bronchi in all components. The enlargement of the lumen of the arteries and veins was accompanied by their full blood. The walls of many vessels were thickened by the swelling of the outer shell. Perivascular edema increased.

\section{Funding}

This research received no external funding.

\section{Acknowledgments}

This research has no acknowledgment.

\section{Conflicts of Interest}

The authors declare no conflict of interest.

\section{References}

1. Mujahid, S.N.; Heber, C.; Volpe, M.V.. MiR-221 and miR-130a Regulate Lung Airway and Vascular Development. PLoS ONE. 2013, 8, 55-59, https://doi.org/10.1371/journal.pone.0055911.

2. Ninomiya, K.; Arimura, H. Homological radiomics analysis for prognostic prediction in lung cancer patients. Physica Medica. 2020, 69, 90-100, https://doi.org/10.1016/j.ejmp.2019.11.026.

3. Karayama, M.; Naoki, I.; Kazutaka, M.; Masato, K.; Hironao, H.; Yuzo, S.; Furuhashi, K.; Hashimoto, D.; Enomoto, N.; Fujisawa, T.; Nakamura, Y.; Watanabe, H. Suda T. Respiratory impedance is correlated with morphological changes in the lungs on three-dimensional CT in patients with COPD. Sci. Rep. 2017, 7, 4147, https://doi.org/10.1038/srep41709.

4. Wu, D.; Wu, C.; Zhong, Y. The association between paraoxonase 1 activity and the susceptibilities of diabetes mellitus, diabetic macroangiopathy and diabetic microangiopathy. J Cell Mol Med. 2018, 22, 42834291, https://doi.org/10.1111/jcmm.13711.

5. Cohen Atsmoni, S.; Brener, A.; Roth, Y. Diabetes in the practice of otolaryngology. Diabetes Metab Syndr. 2019, 13, 1141-1150, https://doi.org/10.1016/j.dsx.2019.01.006.

6. Zvershanovskiǐ, F.A.; Zhulkevich, I.V.; Danilishina, V.S.; Zhulkevich, G.D. Indicators of lipid metabolism and their relation to disorders of microcirculation in diabetes mellitus. Problemy Endokrinologii. 1987, 33, 15-18.

7. Nam, H.W.; Cho, Y.J.; Lim, J.A.; Kim, S.J.; Kim, H.; Sim, S.Y.; Lim, D.G. Functional status of immune cells in patients with long-lasting type 2 diabetes mellitus. Clin Exp Immunol. 2018, 194, 125-136, https://doi.org/10.1111/cei.13187.

8. Anupam, K.; Kaushal, J.; Prabhakar, N.; Bhatnagar, A. Effect of redox status of peripheral blood on immune signature of circulating regulatory and cytotoxic $\mathrm{T}$ cells in streptozotocininduced rodent model of type I diabetes. Immunobiology. 2018, 223, 586-597, https://doi.org/10.1016/j.imbio.2018.07.004.

9. Amal Abd El-Azeem, I. Pulmonary function changes in diabetic lung. Egyptian Journal of Chest Diseases and Tuberculosis. 2013, 62, 513-517, https://doi.org/10.1016/j.ejcdt.2013.07.006.

10. Forgiarini, L.A.; Kretzmann, N.A.; Porawski, M. Experimental diabetes mellitus: oxidative stress and changes in lung structure. J. Bras. Pneumol. 2017, 35, 788-791, https://doi.org/10.1590/s180637132009000800011.

11. Al-Malki, A.L. Oat attenuation of hyperglycemia-induced retinal oxidative stress and NF-kkB activation in streptozotocin-induced diabetic rats. Hindawi Publishing Corporation. Evidence-Based Complementary and Alternative Medicine. 2013, 2013, 8, https://doi.org/10.1155/2013/983923.

12. Lazarenko, V.A.; Lipatov, V.A.; Blinkov, Y.; Skorikov, D.V. An experimental model of common fecal peritonitis. Chelovek i yego zdorovye. 2008, 4, 128-132. 
13. Logoyda, L.; Kondratova, Y.; Korobko, D.; Susla, O.; Soroka, Yu.; Tsytsiura, R.; Pidruchna, S. Youden’s test of the chromatographic determination of captopril in pharmaceuticals. International Journal of Green Pharmacy. 2017, 3, 188-191, http://dx.doi.org/10.22377/ijgp.v11i03.1124.

14. Yue, X.; Liu, S.; Liu, S.; Yang, G.; Li, Z.; Wang, B.; Zhou, Q. HRCT morphological characteristics distinguishing minimally invasive pulmonary adenocarcinoma from invasive pulmonary adenocarcinoma appearing as subsolid nodules with a diameter of $\leq 3 \mathrm{~cm}$. Clin Radiol. 2018, 73(4), 411.e7-411.e15, https://doi.org/10.1016/j.crad.2017.11.014.

15. Bayoumy, A.M.; Youssif, G.; Elgohary, E.A.; Husien, S.; El Deen, H.S.; Albeltagy, N.M.; Abdelnaby, D.R.; Hanan, E.; Ibrahim, M.A. Impact of solvation on the geometrical parameters of some amino acids. Letters in Applied NanoBioScience. 2019, 2, 567-570, https://doi.org/10.33263/LIANBS82.567570.

16. Emadi, H.; Mobarak, H. Synthesis and characterization of copper ferrite nanoparticles and its application as MRI contrast agent. Letters in Applied NanoBioScience. 2019, 1, 541-544, https://doi.org/10.33263/LIANBS81.541544.

17. Logoyda, LS.; Kovalenko, S.; Abdel-Megied, A.M.; Zhulkevych, I.V.; Drapak, I.; Demchuk, I.; Netsyuk, O. HPLC Method Development for the Analysis of Bisoprolol in Combined Dosage Form Containing Bisoprolol and Enalapril and in Vitro Dissolution Studied. International Journal of Applied Pharmaceutics. 2019, 11(3), 186-194. https://doi.org/10.22159/ijap.2019v11i3.32391

18. Yuryeva, O.; Kondratova, Y.; Logoyda, L. Development of high-performance liquid chromatography method for simultaneous analysis of amlodipine and valsartan in combined dosage form and in vitro disslotution studies. Asian Journal of Pharmaceutical and Clinical Research. 2018, 11, 200-204, https://doi.org/10.22159/ajpcr.2018.v11i5.24443.

19. Chidambaram, S.; Thenrajan, R.; Benedict, L.; Ramkumar, P. Formulation and evaluation of Prednisolone retention enema as dispersible tablet and vehicle for the treatment of ulcerative colitis. Letter in Applied NanoBioScience. 2019, 8, 545-552. https://doi.org/10.33263/lianbs82.545552.

20. Rania, B.; Sherif, E.; Hanan, E.; Nadra, N.; Medhat, I.. On the molecular modeling analyses of sodium carboxymethyl cellulose treated with acetic acid. Letter in Applied NanoBioScience. 2019, 8, 553-557. https://doi.org/10.33263/LIANBS82.553557.

21. Kondratova, Y.; Logoyda, L.; Voloshko, Y.; Abdel-Megied, A.; Korobko, D.; Soroka, Y. Development and validation of HPLC-DAD method for the determination of bisoprolol in tablet dosage forms. Int J App Pharm. 2017, 9, 54-59. https://doi.org/10.22159/ijap.2017v9i6.21616.

22. Vaŭnsteĭn, S.G.; Zhulkevich, I.V.; Dubkin, M.S.; Cherno, N.K. Food fibers as modifiers of homeostasis in patients with diabetes mellitus. Terapevticheskii Arkhiv. 1987, 59(11), 29-31.

23. Südy, R.; Schranc, A.; Fodor, G.H.; Tolnai, J.; Babik, B.; Peták, F. Lung volume dependence of respiratory function in rodent models of diabetes mellitus. Respiratory Research. 2020, $21,82$. https://doi.org/10.1186/s12931-020-01334-y.

24. Vaĭnshteĭn, S.G.; Masik, A.M.; Zhulkevich, I.V. Food Fiber-Research Results and Outlook.Vopr. Pitan. 1988, (6), 8-12.

25. Tergast, T.L.; Laser, H.; Gerbel, S.; Manns, M.P.; Cornberg, M.; Maasoumy, B. Association Between Type 2 Diabetes Mellitus, HbA1c and the Risk for Spontaneous Bacterial Peritonitis in Patients with Decompensated Liver Cirrhosis and Ascites. Clinical and Translational Gastroenterology. 2018, 9, 189. https://doi.org/ doi:10.1038/s41424-018-0053-0.

26. Dyson, P.A.; Twenefour, D.; Breen, C.; Duncan, A.; Elvin, E.; Goff, L.; Hill, A.; Kalsi, P.; Marsland, N.; McCardle, P.; Mellor, D.; Oliver, L.; Watson, K. Diabetes UK evidence-based nutrition guidelines for the prevention and management of diabetes. Diabet Med. 2018, 35(5), 541-547. https://doi.org/doi:10.1111/dme.13603.

27. Feketeova, E.; Li, Z.; Joseph, B.; Shah, R.; Spolarics, Z.; Ulloa, L. Dopaminergic control of inflammation and glycemia in sepsis and diabetes. Front. Immunol. 2018. https://doi.org/10.3389/fimmu.2018.00943.

28. Qureshi, M.; Gammoh, E.; Shakil, J.; Robbins, R. Update on Management of Type 2 Diabetes for Cardiologists. Methodist debakey cardiovasc j. 2018, 14(4), 273-280. doi:10.14797/mdcj-14-4-273.

29. Tanaka, Y.; Takagi, R.; Ohta, T.; Sasase, T.; Kobayashi, M.; Toyoda, F.; Shimmura, M.; Kinoshita, N.; Takano, H.; Kakehashi, A. Pathological Features of Diabetic Retinopathy in Spontaneously Diabetic Torii Fatty Rats. Journal of Diabetes Research. 2019. https://doi.org/10.1155/2019/8724818.

30. Li, D.; Song, L.-L.; Wang, J.; Meng, Ch.; Cui, H.-G. Adiponectin protects against lung ischemia-reperfusion injury in rats with type 2 diabetes mellitus. Molecular medicine reports. 2018, 17, 7191-7201. https://doi.org/10.3892/mmr.2018.8748.

31. DiMeglio, L.A.; Evans-Molina, C.; Oram, R.A. Type 1 diabetes. Lancet. 2018, 391(10138), $2449-2462$. https://doi.org/doi:10.1016/S0140-6736(18)31320-5.

32. American Diabetes Association. Classification and Diagnosis of Diabetes: Standards of Medical Care in Diabetes - 2018. Diabetes Care. 2018, 41(Suppl. 1), S13-S27. https://doi.org/10.2337/dc18-S002.

33. Valencia-Sánchez, L.; Almendra-Pegueros. R.; R-Valdez, L.J.D.; Esmer-Sánchez. D.; Medina. Ú.; GordilloMoscoso. A. DPP-4 as a Possible Biomarker of Inflammation Before Abdominal Surgery for Chronic Pathology: Our Experience with Elective Cholecystectomy. Medicina. 2019, 55, 148. https://doi.org/doi:10.3390/medicina55050148. 
34. VanBaak, K.D.; Nally, L.M.; Finigan, R.T.; Jurkiewicz, C.L.; Burnier, A.M.; Conrad, B.P.; Khodaee, M.; Lipman, G.S. Wilderness medical society clinical practice guidelines for diabetes management. Wilderness Environ Med. 2019, 30(4S), S121-S140. https://doi.org/10.1016/j.wem.2019.10.003. 